\title{
Efficient energy management in smart micro-grids: ZERO grid impact buildings
}

\author{
Pablo Arboleya, Senior Member, IEEE Cristina Gonzalez-Moran, Member, IEEE Manuel Coto, Member, IEEE, \\ Maria Carmen Falvo, Senior Member, IEEE Luigi Martirano, Senior Member, IEEE \\ Danilo Sbordone, Ilaria Bertini, and Biagio Di Pietra
}

\begin{abstract}
In a smart micro-grid (MG) each generator or load has to take part into the network management, joining in reactive power supply/voltage control, active power supply/frequency control, fault ride-through capability and power quality control. The present paper includes a new concept for building integration in MGs with zero grid-impact so improving the MG efficiency. These aims are shown to be achievable with an intelligent system, based on a DC/AC converter connected to the building Point of Coupling (PC) with the main grid. This system can provide active and reactive power services also including a DC link where storage, generation and loads can be installed. The system employed for validation is a prototype available at ENEA labs (Italian National Agency for New Technologies). A complete and versatile model in MATLAB/SIMULINK is also presented. The simulations results and the experimental test validation are included. The trial confirms the model goodness and the system usefulness in MG applications.
\end{abstract}

Index Terms-Green Buildings, Electrical Energy Distribution, Steady-State Modeling, Dispersed Generation, Energy Storage, Smart Micro-Grids, Simulation.

\section{NOMENCLATURE}

\section{Acronyms \\ BMS Battery Management System. \\ CHP Combined Heat and Power. \\ CPD Custom Power Device. \\ DG Dispersed Generation. \\ DSO Distribution System Operator.}

DSTATCOMDistribution Static synchronous compensator.

ENEA Italian National Agency for New Technologies Energy and Sustainable Economic Development.

LV Low voltage.

MG Microgrid.

MPPT Maximum power point tracking.

MV Medium voltage.

NZEB Nearly Zero-Energy Building.

PC Point of coupling.

PHEV Plug-In Hybrid Electrical Vehicles.

PI Proportional-integral.

PLL Phase locked loop.

P. Arboleya, C. Gonzalez-Moran and M. Coto are with the Department of Electrical Engineering, University of Oviedo, Spain. M.C. Falvo, Luigi Martirano and D. Sbordone are with the Department of Electrical Engineering, University of Rome (La Sapienza), Italy. I. Bertini and B. Di Pietra are with the ENEA (Italian National Agency for New Technologies) e-mail: arboleyapablo@uniovi.es, gonzalezmorcristina@uniovi.es, cotomanuel@uniovi.es, mariacarmen.falvo@uniroma1.it,_luigi.martirano@uniroma1.it, danilo.sbordone@uniroma1.it, ilaria.bertini@enea.it, biagio.dipietra@enea.it Manuscript received XXX, 2014; revised XXX, 2014.
SD Switching device.

TSO Transmision System Operator.

Subscripts

$d, q \quad$ Synchronous reference frame components.

droop Droop slope.

$i \quad$ Integral.

meas Measurement.

$P \quad$ Active Power control gain.

$p_{g} \quad$ Proportional.

$Q \quad$ Reactive Power control gain.

ref Reference.

$S D 1 \quad$ Switching device number 1.

SD2 Switching device number 2.

Superscripts

$A \quad$ Building coupling with the grid.

$B \quad$ Main DC/AC converter coupling with the building AC grid.

$C \quad$ Main DC/AC converter output.

$D \quad$ DC bus.

LiPo Output of the Lithium-Polymer battery.

$\max \quad$ Maximum allowed value.

$P V \quad$ Output of the photovoltaic module.

Variables

I Current.

$k \quad$ Droop slope or proportional or integral gain.

$P \quad$ Active Power.

$Q \quad$ Reactive Power.

$U \quad$ Voltage.

\section{INTRODUCTION}

In recent years, many changes have occurred in the electricity sector to improve the energy efficiency and environmental sustainability of generation, transport and final use segments, involving the need to update and improve the electric grids [1]-[3]. The first revolution deals with the deregulation of the electrical industry, by means of the markets introduction: the electricity service has been opened to the generation plants owners and also to the final users; this has influenced the operational functions initially belonging to Transmission and Distribution System Operators (TSO, DSO) [4]-[6]. Another important change regards the spread of the so-said Dispersed or Distributed Generation (DG), including renewable sources generation plants (such as photovoltaic or wind micro-turbine) and high efficiency production systems (such as gas microturbine or Combined Heat and Power (CHP)) [7]. The DG 
has had a big impact on transmission and distribution grids, in terms of electricity flows and protection systems. The promotion of Nearly Zero-Energy Buildings (NZEBs) construction constitutes another important innovation in the electric grid [8]. NZEB means a building that has a very high energy performance being the low amount of energy required covered to a significant extent by energy from renewable sources and CHP, both for residential and commercial buildings.

In traditional power systems, the reliability impact could be significant when a large amount of variable DG is integrated on it. It is well known that the chaotic phenomena in the existing distribution grids will occur when the DG penetration reach a high level compared to the net energy, causing network congestion and so compromising the energy quality by voltage and frequency disturbances.

For all the above mentioned reasons, the uncertainties associated to markets, DG and PHEVs have to be taken into consideration by the new systems, making possible real interactions between generators, users and grid. The new systems must be implemented to transform the traditional electrical grid into a flexible, open-access and sustainable system, called Smart Grid [9]. The European Union provides this definition: A Smart Grid is an electricity network that can intelligently integrate the actions of all users connected to it -generators, consumers and those that do both-in order to efficiently deliver sustainable, economic and secure electricity supplies. In other words, the evolution of distribution grids through Smart Grids is calling for similar actions adapted to the transmission grids.

At the same time, another concept related to the distribution grid has been proliferating: the Micro-Grid(MG) concept. A MG is a small electricity network, generally in low voltage (LV) level, connected to other MGs and/or to the main grid (generally in medium voltage(MV), using a single point of connection (point of coupling PC). A MG generally includes DG, electrical loads of different types (i.e. PHEVs) and energy storage devices in a reduced space. In a MG, each actor could take part into: reactive power supply and voltage control; active power supply and frequency control; fault ride-through capability and power quality control (flicker, harmonics) [10].

This work presents a new concept for buildings integration in Smartgrids. The proposed system integrates in the same building AC and DC distribution. The two distribution systems are coordinated and connected through a DC/AC converter. the whole system can provide active and reactive power to the building and/or to the main grid among other ancillary services as a reactive compensation functions. The whole building will work as a two coordinated small MG or as a dispatchable load or generator.

The rest of the paper is organised as follows: in section II the electrical system of the building will be described. Also an overview on the main function that a custom power device (CPD) with energy storage can perform in the $\mathrm{MG}$ management is included. In section III, the control of all the system parts is explained. Section IV summarises the simulation results carried out in MATLAB/SIMULINK. In section $\mathrm{V}$, the real prototype that has been used to test the system in a real Smart MG, available at ENEA Labs is described and the obtained measurements during a case of study are discussed. Section VI presents a set of conclusions about the use of CPDs.

\section{SYSTEM DESCRIPTION}

In Fig. 1 the general scheme of the proposed CPD installed at one of the ENEA buildings is depicted. As it can be observed the system has two different parts; the first one is the AC subsystem that is connected to the main grid and to the building loads. The second part is the DC subsystem where the energy storage system based on Lithium-Polymer batteries (LiPo Battery) is installed. In the DC side there are also DC loads, a Voltage Limiter Resistor (VLR) for overvoltage protection and a photovoltaic generator (PV module). This last element is not installed in the real prototype yet, however, it is included in simulations to study the effect of such generation over the whole system. In Fig. 2, a photograph of the real prototype is shown.

In the next subsections the different elements that compose the CPD will be described.

\section{A. Li-Po Batteries}

The energy storage system is based on Lithium-Polymer (LiPo) batteries. The whole module is constituted by 280 cells connected in series with a rated energy storage of $70 \mathrm{Wh}$ per cell. The total pack capacity is $16 \mathrm{kWh}$. The system is able to discharge at a maximum rate of $20 \mathrm{~kW}$ in 15 minutes or $10 \mathrm{~kW}$ in an hour. The ratio between the maximum output power and the rated energy is $4-8 h^{-1}$. The maximum operating temperature is $45^{\circ} \mathrm{C}$ at a relative humidity range of $40-90 \%$. The estimated life is about 2000 cycles at $80 \%$ discharge. The batteries pack rated voltage is $270 \mathrm{~V}$ at full charge. However, the pack is split into several sections with voltages not greater than 60V. As it can be observed in Fig. 2, the batteries location facilitates the manual access to all accumulator terminals.

The battery pack is connected to the $600 \mathrm{~V}$ DC bus using a bidirectional $D C-D C$ Buck-Boost converter whose topology can be observed in Fig. 3a). The battery management system (BMS) controls the converter trying to keep a constant voltage in the DC bus but limiting the charge and discharge rate to ensure the correct operation of the battery pack. A detailed explanation of this control will be given in the next section. The BMS acquires the cells voltage, current and temperature so it also estimates the storage system state of charge.

The DC bus over-voltage protection is also ensured by a $60 \Omega$ VLR of $60 \Omega$ connected by means of a chopper. The scheme of this protection is depicted in Fig. 3c) and its control will be also described in next section.

\section{B. Main $A C-D C$ converter}

The power converter has been built using solid state static components; it is equipped with IGBTs. The switching overvoltages must not exceed $200 \mathrm{~V}$ at full power. For this purpose special limiting circuits are included. IGBTs are also equipped with detection circuit desaturation. The detection saturation has been locally done with a hardware circuit connected to the 


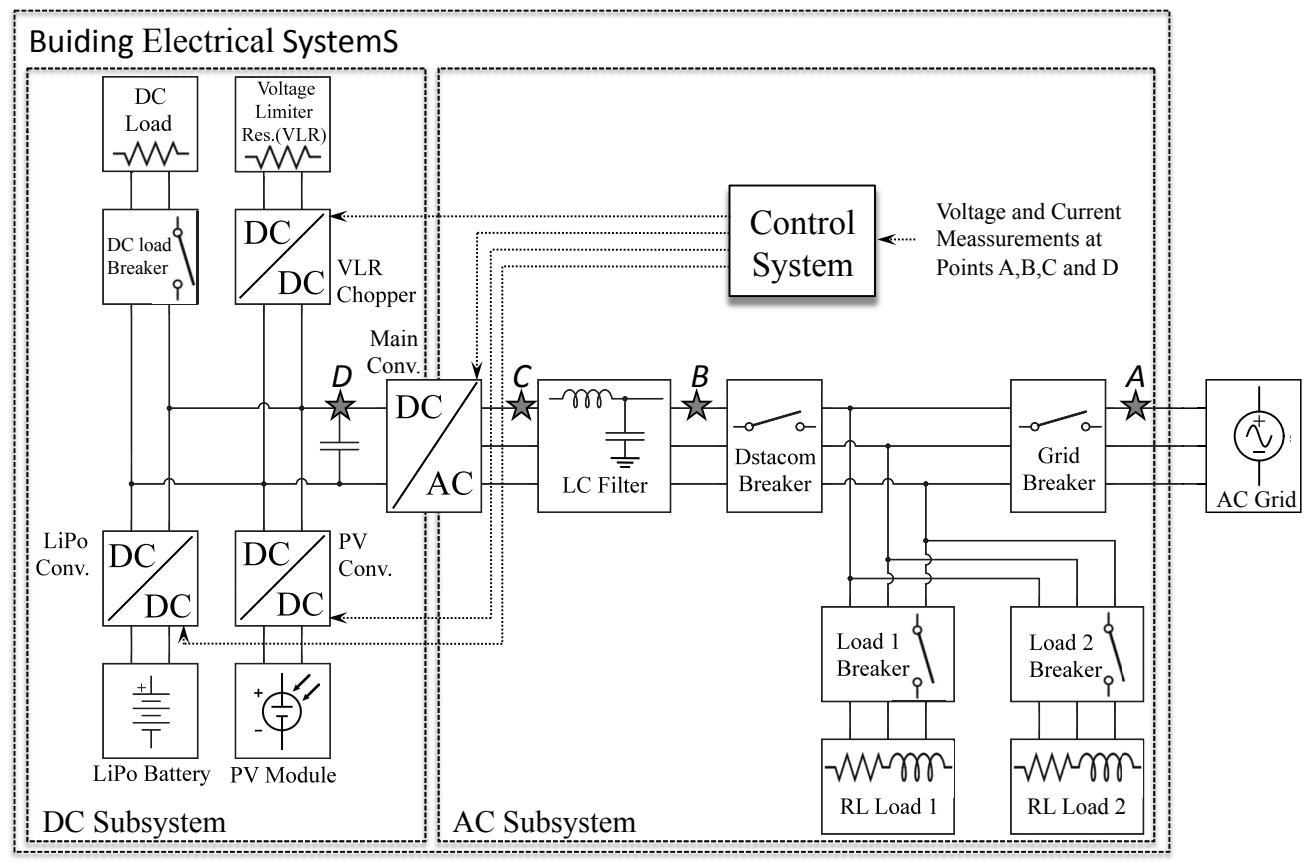

Fig. 1: General scheme of the CPD (Customer Power Device).

anode of each transistor and must lead to the immediate arrest of its conduction. At the same time a blocking signal should be sent, via the logic control, to arrest of the whole converter. The overheating protection of the device is implemented with temperature sensors inside the semiconductor module. The static converter is provided with appropriate input and output filters for suppressing disturbances, according to the directives 89/336/EEC and 92/31/EEC. The connection to the 400V AC grid is complied with the requirements of the Italian Standard CEI 0-21. The 600V DC bus-bar is sized to connect both a DC load with a maximum power of $20 \mathrm{~kW}$ and a production system with a maximum power of $30 \mathrm{~kW}$.

A detection and protection system provides the information about the components status: power supply for the electronics out of range, communication error with DSP, bar voltage out of range, inverter over-temperature, leakage currents to ground, gear time out, inverter over-current, protection IGBT modules, thermal protection inverter, line voltage out of range and low line voltage alarm.

The control of the main converter will be deeply described in next section.

\section{Loads}

The loads are placed at the AC side and at the DC side of the main converter. In the AC side the load is the ENEA building consumption, that can oscillate between $36 \mathrm{~kW}$ and $228 \mathrm{~kW}$. In the DC side, the loads are composed by some auxiliary DC loads being the most important the system ventilation. The total amount of DC load is about $5 \mathrm{~kW}$.

\section{SYSTEM CONTROL DESCRIPTION}

In this section all the system controls and the interaction between them will be described. In Fig. 1, a general overview

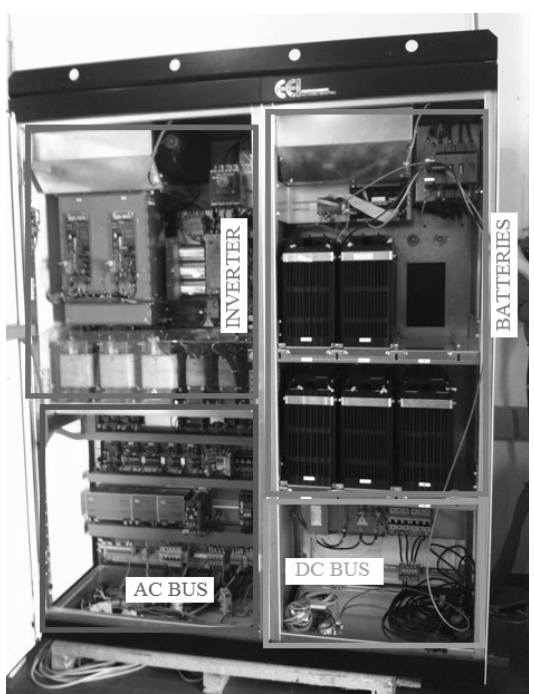

Fig. 2: Real prototype installed at ENEA labs.

of the system was presented, and as it was previously stated, the only difference between the modelled system and the real prototype is the PV generator connected to the DC side.

As it can be observed in Fig. 1, there are basically four points of measurement for voltages and currents, $(A, B, C$ and $D$ ). The voltages and currents at the $\mathrm{PC}$ (point $A$ ) are measured to calculate the power that the building injects or demands from the network. Measurements at B are used to control the transferred power from the $\mathrm{DC}$ to the $\mathrm{AC}$ side of the system or vice versa. The currents at $\mathrm{C}$ are also needed to implement the current control of the main converter. Finally the DC bus voltage will be acquired at D.

The magnitudes needed at each device control will be 


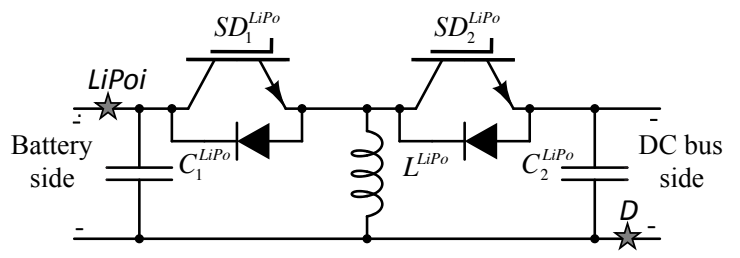

a)

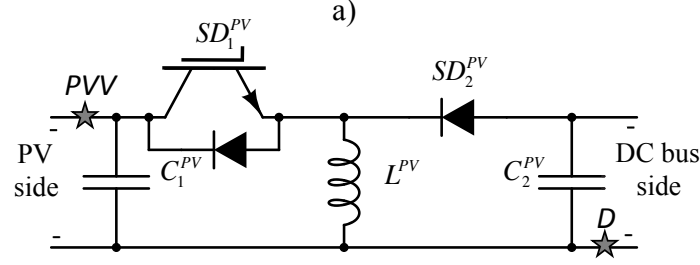

b)

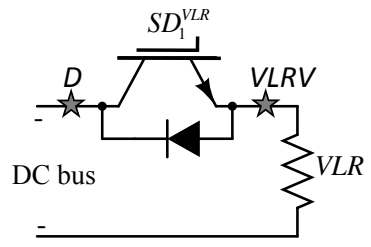

c)

Fig. 3: Converter topologies used in the DC subsystem. a) Bidirectional $D C-D C$ Buck-Boost converter that connects the Lithium-Polymer battery with the DC bus. b) Unidirectional $D C-D C$ Buck-Boost converter that connects the Photovoltaic module with the DC bus. c) Chopper for activating the Voltage Limiter Resistor.

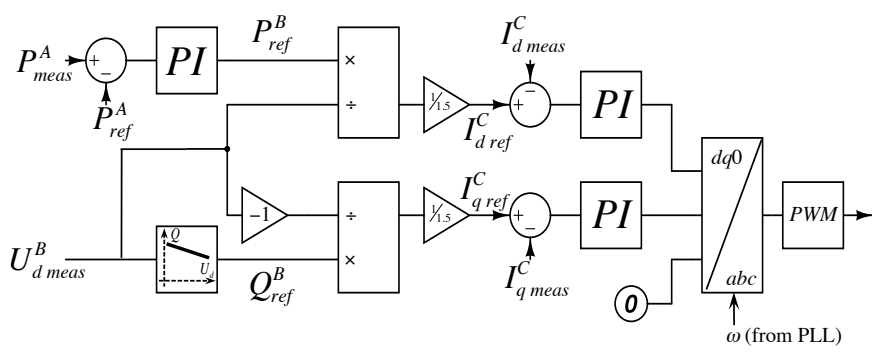

Fig. 4: Control of the DC/AC main converter.

enumerated in next subsections.

\section{A. Main converter control}

In Fig. 4, the basic control system of the $A C / D C$ main converter can be observed. It is basically a PQ control over an inner current loop control.

The active and reactive power references are calculated as follows:

$$
\begin{gathered}
P_{\text {ref }}^{B}=\left(k_{p, P}+\frac{k_{i, P}}{s}\right) \cdot\left(P_{\text {meas }}^{A}-P_{\text {ref }}^{A}\right) \\
Q_{\text {ref }}^{B}=Q_{0}^{B}-k_{\text {droop }, Q} \cdot\left(U_{d, \text { meas }}^{B}-U_{d, 0}\right)
\end{gathered}
$$

The measured active and reactive powers at A are considered positive if the building is consuming. Thus, if the power that the building is demanding is greater than the reference at A set by the building management system, the active power reference of the main converter (at B) will be increased. The configuration of the proportional and integral gains of this control $\left(k_{p_{g}, A C}\right.$ and $\left.k_{i, A C}\right)$, is critical because when a fast response is desired the DC bus voltage could become unstable, so a properly coordination between this control and the battery control must be assured.

Regarding the reactive power a droop control is implemented (2). If the PC voltage is equal to the rated voltage $\left(U_{d, 0}\right)$ no reactive power is injected to the $\mathrm{AC}$ side. If the measured voltage is lower than the rated, the main converter will inject a reactive power proportional to the difference between the rated and the measured powers. The proportionality constant will be the slope $k_{d r o o p, Q} . U_{d, 0}^{B}$ and $Q_{0}^{B}$ are the rated voltage and the injected reactive power at rated voltage that is set to zero in a general case. These three parameters $k_{d r o o p, Q}$, $U_{d, 0}^{B}$ and $Q_{0}^{B}$ are implicit in the droop equation (2), represented also in the droop block in Fig. 4. The opposite behaviour is obtained when the measured voltage is greater than the rated. Using this control not only the active power that is exchanged with the grid is controlled, but also a reactive power supporting to the main grid is assured. If the reactive power support is not needed the control can be deactivated giving zero value to the reactive power reference. Another possibility could be the use of a reactive power control similar to the one described for the active power, allowing the system to work with a fixed power factor.

Once the active and reactive power references are set (Fig. 4), the current references are calculated. In this case, a phase locked loop (PLL) is configured to straighten the $d, q$ references with the measured voltage so this means that $\left(U_{q, \text { meas }}^{B}=0\right)$ and the current references can be calculated as follows:

$$
\begin{aligned}
I_{d, \text { ref }}^{C} & =\frac{P_{r e f}^{B}}{1.5 \cdot U_{d, \text { meas }}^{B}} \\
I_{q, \text { ref }}^{C} & =\frac{-Q_{r e f}^{B}}{1.5 \cdot U_{d, \text { meas }}^{B}}
\end{aligned}
$$

An overcurrent protection and a DC bus voltage protection are also implemented, limiting the active power reference when the DC bus voltage drops below a preset value.

\section{B. Lithium-Polymer battery control}

The Lithium-Polymer battery is connected to the DC bus by means of a bidirectional $D C / D C$ Buck-Boost converter as it is depicted in Fig. 3a). In this case, the voltage polarity is inverted. To control the charge/discharge of the battery, the voltage and current at point D (DC bus) are needed, but also the voltage and current at the battery terminals labeled in this case as $(\mathrm{LiPo})$.

The power flow is controlled by the duty cycles $\left(D_{S D 1}^{L i P o}\right.$ and $\left.D_{S D 2}^{L i P o}\right)$ of the IGBT switching devices labeled as $S D_{1}^{L i P o}$, and $S D_{2}^{L i P o}$. 


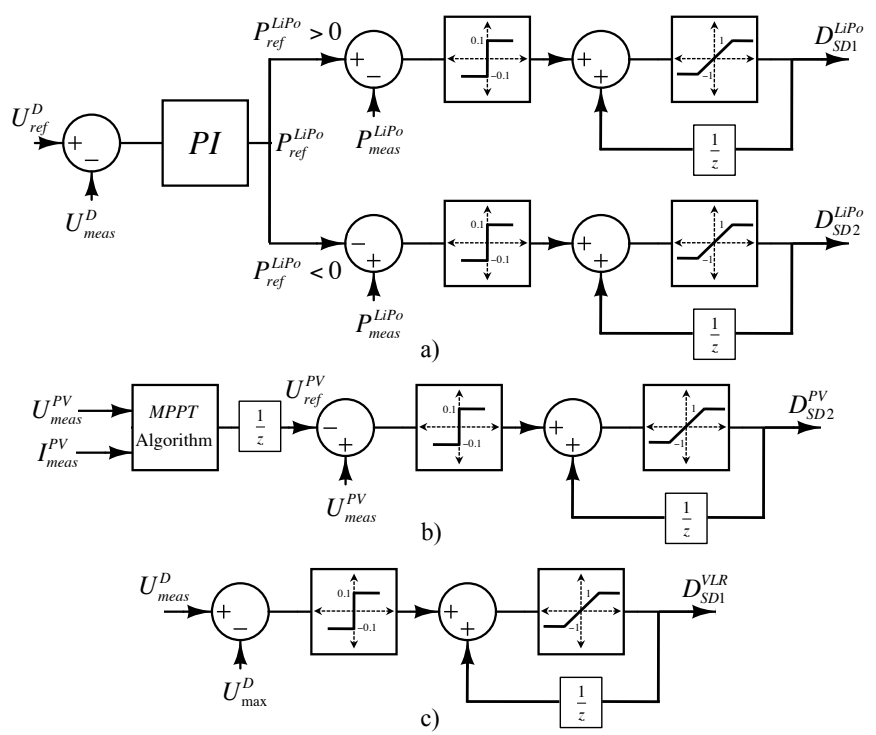

Fig. 5: Control of DC/DC converters. a) LiPo DC/DC converter control. b) PV DC/DC converter control. c) Voltage Limiter Resistor (VLR) chopper control.

The switching devices are not fired at the same time. When the discharge of the battery is required, $S D_{1}^{L i P o}$ is controlled and $S D_{2}^{L i P o}$ duty cycle is set to zero. On the other side, if the battery has to be charged, the control actuates over $S D_{2}^{L i P o}$ duty, switching $S D_{1}^{L i P o}$ off.

In Fig. 5a) $S D_{1}^{L i P o}$ and $S D_{2}^{L i P o}$ controls are represented. To determine if the power reference $P_{r e f}^{L i P o}$ is positive or negative the measured DC bus voltage $U_{\text {meas }}^{D}$ is subtracted from the reference $U_{r e f}^{D}$ and the error is conducted through a $P I$. The $P I$ output is the power reference $P_{r e f}^{L i P o}$. If it is positive, the battery must be discharged to increase the DC bus voltage. Then, the power reference $P_{r e f}^{L i P o}$ is compared with the measured value $P_{\text {meas }}^{\mathrm{LiPo}}$ and if the reference is higher, $S D_{1}^{L i P o}$ duty $\left(D_{S D 1}^{L i P o}\right)$ will be increased in steps of 0.1 . The battery protection system will limit the power reference as well as the current and voltage. As long as the power reference is positive, $S D_{2}^{L i P o}$ duty will be set to zero.

If the power reference is negative, the battery must be charged. Again, if the measured rate of charge is lower than the reference, $S D_{2}^{L i P o}$ duty will be increased in steps of 0.1, on contrary the duty will be reduced. While the battery is charging $S D_{1}^{L i P o}$ duty is set to zero.

With the described method there is no need of communication between the main converter and battery controls because the former transfers the active power necessary to control the building net power and the latter will keep stable the DC bus voltage.

\section{PV module control}

The PV module is connected to the DC bus through an unidirectional $D C / D C$ Buck-Boost converter. In Fig. 3b) the topology of this converter is presented. If the converter is compared with the bidirectional one used in the battery, the only difference is that the second switching device has been replaced by a diode.
In this case, the control system just actuates over the $S D_{1}^{P V}$ duty cycle. To calculate the duty, a maximum power point tracking (MPPT) algorithm is used to extract the maximum available power at the PV module. The MPPT inputs are the $\mathrm{PV}$ module terminals voltage and current $\left(U_{\text {meas }}^{P V}\right.$ and $\left.I_{\text {meas }}^{P V}\right)$. The output is the PV terminals voltage reference necessary to extract the maximum power $U_{r e f}^{P V}$.

The system works at the point in which the derivative of the voltage with respect to power is zero. If $d P / d U>0$ the voltage must be increased and if $d P / d U<0$ the voltage must be decreased.

If the reference voltage is higher than the measured value, $S D_{1}^{P V}$ duty will be reduced, otherwise it will be increased. An scheme of the control system is depicted in Fig. 5b). Anyway, with this topology the power always flows from the PV module to the DC bus. A detailed description of the PV model and the MPPT algorithm can be found in [11].

\section{Voltage resistor limiter (VRL) control}

The voltage resistor limiter is activated through a chopper such as the one in Fig. 3c). As it can be observed in 5c). When the measured DC voltage $U_{\text {meas }}^{D}$ is greater than a preset maximum value $U_{\max }^{D}$, the $S D_{1}^{V L R}$ duty is increased in steps of 0.1. As it is going to be analyzed in the next section, the battery rate of charge is limited for security reasons. As a consequence, to reduce the DC voltage when the load is suddenly reduced, part of the energy must be burned in the VRL. This system is designed to assist the battery to control the transient DC bus voltage rises. However, if the system is properly sized and designed, it should not work during the steady state condition.

\section{ANALYSIS OF THE SYSTEM BEHAVIOR}

A MATLAB/SIMULINK model of the proposed system was implemented in order to test the controls. The model will be later validated with the real prototype. The only difference between the model and the prototype is that the model also includes a PV generator.

The PV generator is modelled as a 34 modules connected in series. Each module is formed by 60 series cells of $218 W_{p}$. The model parameters were obtained from the SLK60P6L module sheet of characteristics, manufactured by SILIKEN. The mathematical model is the so called single diode five parameters. Further details about its implementation in MATLAB/SIMULINK can be found in [11].

Both the AC and the DC loads are considered as constant impedance. For this reason, in the simulation results it can be seen that a change in the DC voltage or grid voltage will provoke a change in the power absorbed by the DC load or the AC load respectively. The AC load has been modelled as two parallel RL loads being the first one(load 1): $R=50 \Omega$ and $X=50 \Omega$, and the second one (load 2): $R=100 \Omega$ and $X=100 \Omega$. Both of them can be connected or disconnected using load 1 or load 2 breakers. The DC load is modelled as a resistor $R=60 \Omega$ and can be also connected or disconnected using the DC load breaker. 


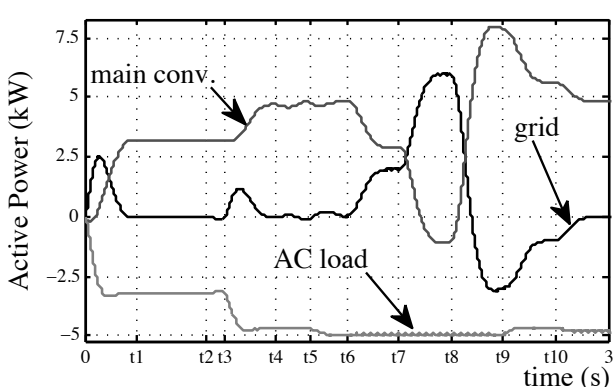

a)

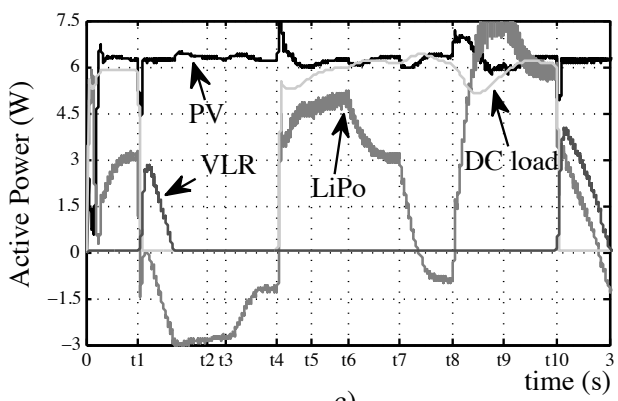

c)

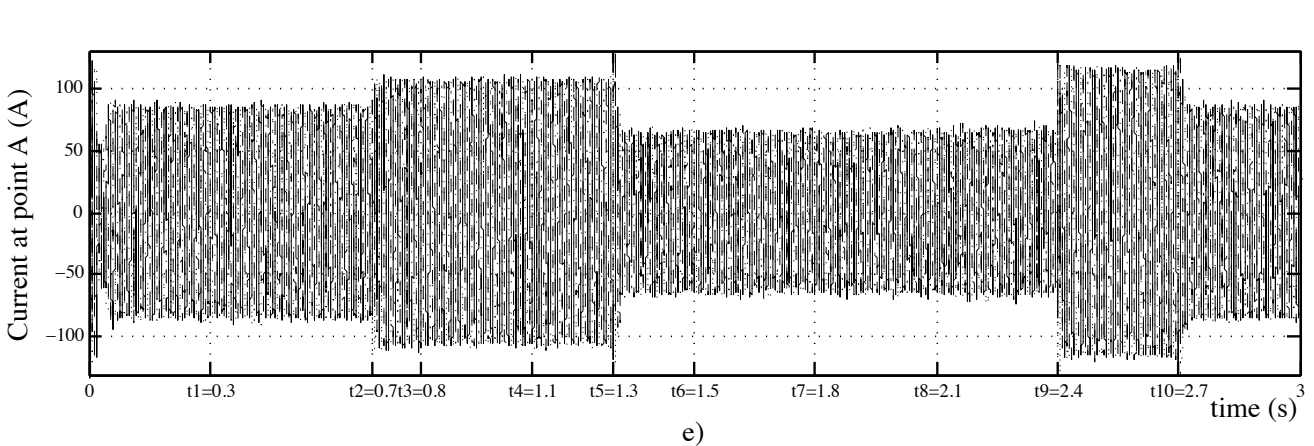

e)

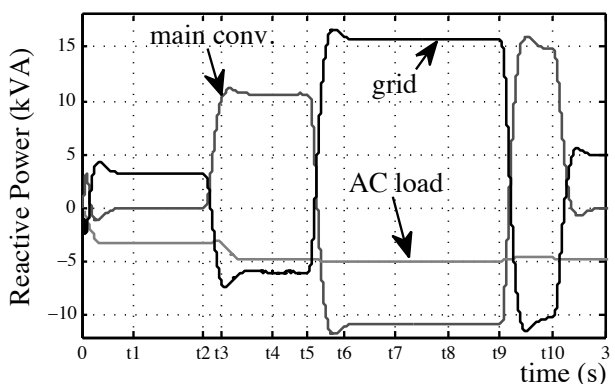

b)

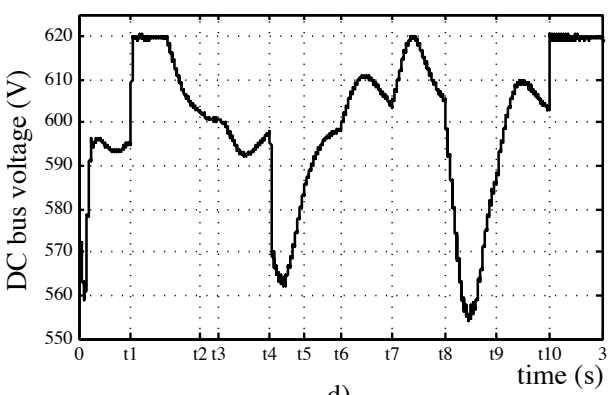

d)

Fig. 6: Case of study. a) Active Power at the AC part of the system (kW). b) Reactive Power at the AC part of the system $(\mathrm{kVA})$. c) Active Power at the DC part of the system (kW). d) DC bus voltage (V). ABC injected in the AC system by the main converter (at point B).

In Fig. 6, a case of study is analysed. The simulation time is 3 seconds in which 10 different events occur. During the simulation, $U_{r e f}^{D}$ is set to $600 \mathrm{~V}$ and the maximum DC voltage $U_{\max }^{D}$ is $620 \mathrm{~V}$. The maximum voltage has been chosen to illustrate the system behaviour when it is reached.

In $t=0$ the system is activated with a $P_{r e f}^{B}$ set to zero, load 1 breaker is closed and load 2 breaker is opened. Since the voltage at the $\mathrm{AC}$ subsystem is equal to its rated value $(400 \mathrm{~V})$, the load 1 will absorb $3.2 \mathrm{~kW}$ and $3.2 \mathrm{kVA}$. At the beginning, part of the power is extracted from the grid because the speed of response of the main converter is limited to preserve the DC bus voltage stability. That is why up to $2.5 \mathrm{~kW}$ are absorbed from the grid at the first time instants, but before $t_{1}$ is reached the main converter provides the required $3.2 \mathrm{~kW}$, and the active power from the grid becomes zero (see Fig 6.a)). Since the voltage in the AC subsystem is equal to its rated value, no reactive power will be injected/absorbed by the main converter due to droop control, being the reactive power required by the AC load (3.2 kVA) obtained from the grid (see Fig 6.b)).

In the DC bus, the PV module is working with fixed irradiation at $1000 \mathrm{~W} / \mathrm{m}^{2}$ and temperature at $298 \mathrm{~K}$. Under these conditions, the PV module is injecting $6.4 \mathrm{~kW}$ to the DC bus. The rated DC load is $6 k W$, however the voltage is about $595 \mathrm{~V}$, so the DC load will absorb $5.9 \mathrm{~kW}$. In the DC bus there is an extra generation of $0.5 \mathrm{~kW}$ and $P_{\text {ref }}^{B}$ is still set to zero, so the main converter has to transfer $3.2 \mathrm{~kW}$ from the DC part to the AC part, for this reason $2.7 \mathrm{~kW}$ must be extracted from the battery. The battery power reference rate of change is limited and during the first instants, so power provided by the battery is lower than $2.7 \mathrm{~kW}$ (see Fig 6.c)), and because of this unbalance between power injection and demanded power in the DC bus, the voltage is lower than 600V (see Fig 6.d)).

At $t_{1}=0.3 \mathrm{~s}$, before the steady state is reached, the DC load breaker is opened, at this time the rate of discharge of the battery is approximately $3 k W$ and the PV module is injecting $6.4 \mathrm{~kW}$, the power reference is not changed at the main converter, so the DC part has to provide the $3.2 \mathrm{~kW}$ demanded by the $\mathrm{AC}$ load. The net balance between generation and load at the DC bus, gives a generation excess of $6.2 \mathrm{~kW}$, provoking a rapid voltage rise in the DC bus at the time 
that the DC load is disconnected $\left(t_{1}\right)$. When the DC voltage reach the maximum value $(620 \mathrm{~V})$, the chopper connects the resistor to burn the required power to drop the voltage below the maximum. At the same time the battery power reference begins to change in order to work in charging mode and absorb the extra power. The peak power absorbed by the VLR is $3 k W$, once the battery begins to absorb power and the VLR is disconnected. Before reaching $t_{2}$ and the steady state is nearly reached. The PV module is injected $6.4 k W$ the AC load is absorbing $3.2 \mathrm{~kW}$ and the battery is charging at a $3.2 \mathrm{~kW}$ rate. The DC voltage is being reduced at nearly $600 \mathrm{~V}$. Analysing the AC part between $t_{1}$ and $t_{2}$, no change is observed since the main converter power reference is not changed and the AC voltage remains at is rated value.

At $t_{2}=0.7 \mathrm{~s}$ the AC voltage suffers a drop of $5 \mathrm{~V}$. Intermediately, the main converter begins to inject reactive power trying to compensate this voltage drop. At the DC part, no important changes are observed. The amplitude of currents injected in the system by the main converter increase as it can be observed in Fig. 6e). Due to the droop configuration, a change of $5 \mathrm{~V}$ in the voltage will produce a variation of $12 k V A$. At steady state, the main converter would inject $12 k V A$ and the AC load would absorb $3.2 k V A$, so $8.8 k V A$ would be injected to the main grid.

At $t_{3}=0.8$ the second $\mathrm{AC}$ load is connected when the steady state has not been reached yet. Both AC loads will absorb $4.7 \mathrm{~kW}$ and $4.7 \mathrm{kVAr}$. At the first instants part of the active power is absorbed from the grid because the rate of variation of the power reference at the main converter is limited to guaranty the voltage stability at the DC bus. In the DC bus, the PV module is generating $6.2 \mathrm{~kW}$ and the battery rate of charge is reduced to $1.5 \mathrm{~kW}$ to inject the rest of the power $(4.7 \mathrm{~kW})$ to the $\mathrm{AC}$ part. Regarding the reactive power, the main converter injects $12 k V A$ and the load absorbs $4.7 \mathrm{kVA}$, so the extra reactive power $6.3 \mathrm{kVA}$, is injected into the network.

At $t_{4}=1.1$, the DC load is connected again, now the power balance is the next; the PV panel is generating $6.2 \mathrm{~kW}$, the AC load absorbs $4.7 \mathrm{~kW}$ and the DC load would absorb $5.9 \mathrm{~kW}$. Actually the DC load absorb a lower amount of power during the first instants derived from the voltage drop caused by power unbalance at the time of the DC load connection. The battery will change its working mode, and will start working in discharging mode with a rate of discharge of $4.5 \mathrm{~kW}$ the extra power injected at the DC bus is used to increase the DC bus voltage.

At $t_{5}=1.3 \mathrm{~s}$, the AC voltage is increased in $5 \mathrm{~V}$. At this voltage, the $\mathrm{AC}$ load will consume $5 \mathrm{~kW}$ that will be provided by the main converter since the $P_{\text {ref }}^{A}$ is still zero. Due to the droop control, the main converter will try to reduce the grid voltage absorbing and given amount of reactive power determined by the value of the droop (in this case $12 k V A)$. The grid will provide the reactive power $(5 k V A$ consumed by the load at this voltage level) plus the $12 \mathrm{kVA}$ consumed by the main converter. The total amount of reactive power imported from the grid is about $17 k V A$. There are no significant changes in the DC bus (at $t_{6}$ the voltage is nearly in its rated value $600 \mathrm{~V}$ ).
At $t_{6}=1.5 \mathrm{~s}$ the active power reference at the point labeled as " $A$ " is set to $P_{r e f}^{A}=2 k W$. This means that the building must import $2 k W$ from the network. The load absorbs $5 k W$, $3 k W$ from the main converter and $2 k W$ from the grid. The DC bus voltage is near the rated value so the DC load is absorbing around $6 \mathrm{~kW}$. The $\mathrm{PV}$ is injecting $6.4 \mathrm{~kW}$ and the main converter is transferring $3 k W$ to the $\mathrm{AC}$ part. In this case the battery must provide most of the power transferred from the DC subsystem to the AC one.

At $t_{7}=1.8 \mathrm{~s}$, the active power reference at $A$ is set to $P_{\text {ref }}^{A}=6 k \mathrm{~W}$. In this case, the building is absorbing $6 k \mathrm{~W}$ from the main grid, but the load is only consuming $5 k W$, so the main converter must transfer $1 \mathrm{~kW}$ from the AC part to the DC part. Since the PV generation and the DC load are nearly balanced, the extra power transferred from the AC part is used to charge the battery.

At $t_{8}=2.1 s$, the active power reference at $A$ is set to $P_{\text {ref }}^{A}=-3 k W$, and the whole building will act as a generator. The main converter must supply $5 k W$ demanded by the load plus $3 k W$ that must be injected into the network being the total amount of active power $8 \mathrm{~kW}$. Most of this power must be supplied by the battery, that is why at the first instants, there is an important voltage drop at the DC bus due to the limitations of the battery references rate of change.

At $t_{9}=2.4 \mathrm{~s}$, the active power reference at $A$ is set to $P_{r e f}^{A}=-1 k W$, and the DC voltage is again near the rated value. At the same time the AC voltage suffers a drop of $12 \mathrm{~V}$ (from $405 \mathrm{~V}$ to $393 \mathrm{~V}$ ) so the main converter will become again a reactive power generator, supplying the load requirements plus a grid injection of $10 \mathrm{kVA}$. Reagarding the active power, the main converter will inject $5.5 \mathrm{~kW}$ to the $\mathrm{AC}$ part. $1 \mathrm{~kW}$ is injected into the grid and $4.5 \mathrm{~kW}$ are consumed by the load.

At $t_{10}=2.7 \mathrm{~s}$, the active power reference at $A$ is set to $P_{r e f}^{A}=0$ again, so the building will be invisible for the grid in terms of active power consumption. The grid voltage is set to $400 \mathrm{~V}$, so no reactive power injection will be required from the main converter and the DC load will be switched off. The PV generation will be $6.4 \mathrm{~kW}$ and the AC demand of $4.7 \mathrm{~kW}$ so the extra power will be used to charge the battery. At the first instants after the DC load disconnection, the DC voltage will rise again due to the battery references limitations and the VLR will be activated to limit the voltage rise to its maximum preset value of $620 \mathrm{~V}$.

\section{TESTS WITH THE REAL PROTOTYPE}

As an example, the authors provide in this section some tests developed with the real prototype. In Fig. 7, the obtained data during the tests are depicted. The data correspond to a test carried out for 20 minutes. The building AC load varied in a range from $101 \mathrm{~kW}$ to $120 \mathrm{~kW}$. The $P_{\text {ref }}^{A}$ was set to $105 \mathrm{~kW}$. During the whole test the voltage at the PC was equal to its rated value so there was not reactive power injection. The main converter injected the difference between the power demanded by the load and $P_{r e f}^{A}$. Most of the time, this difference was positive so the main converter transferred power from the DC side to the AC side, but at $t \simeq 360 \mathrm{~s}$. the AC power demand drooped below $P_{r e f}^{A}$ (near $100 \mathrm{~kW}$ ), so the main converter had 

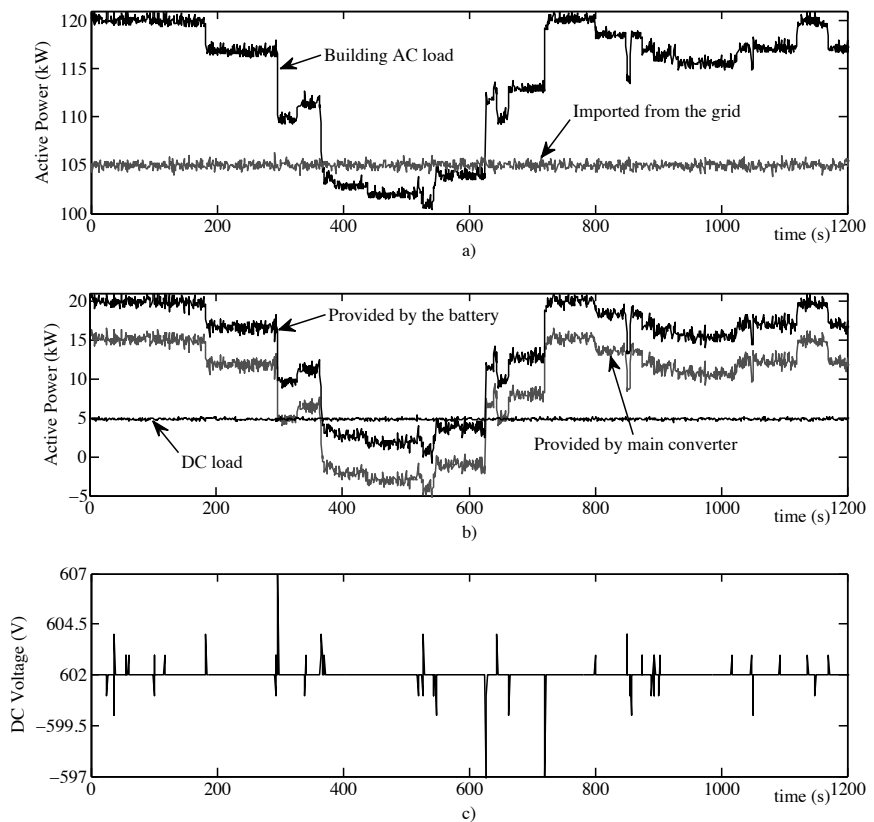

Fig. 7: Case of study. a) Active Power at the AC part of the system (kW). b) b) Active Power at the DC part of the system $(\mathrm{kW})$ and active power provided by the main converter. c) DC bus voltage $(\mathrm{V})$.

to absorb power injecting it into the DC bus. The DC load is $\simeq 4.8 \mathrm{~kW}$, most of this load is used for the ventilation system. All the power into the DC bus through the main converter was used to supply the DC load, during this case of study the battery did not work in charging mode. At $t \simeq 630 \mathrm{~s}$ the building power demand raised again over $P_{r e f}^{A}$ and the main converter began to transfer again active power from the DC part to the AC part of the system. In Fig 7c) the voltage at the DC bus is depicted. It can be observed that when the AC load is reduced the voltage is increased at the DC bus and vice versa. In this case there was an error of $2 \mathrm{~V}$ with respect to the reference in the steady state DC bus voltage and the maximum voltage variation during the test was $\pm 5 \mathrm{~V}$. The sample frequency was $1 \mathrm{~Hz}$.

\section{CONCLusions}

In this paper, a CPD and its operation in a zero grid impact building was presented. This kind of configuration allows the building to control the amount of active and reactive power can be imported or exported from the grid, making the building acting as a dispatchable load or generator. This could be very helpful to achieve large penetration levels of dispersed generation in the low voltage grid. Moreover, the device is also capable of providing ancillary services as voltage support by increasing the reactive power injection when the grid voltage is below its rated value. As it was stated, the proposed device has two different subsystems. The AC subsystem consists on the building AC loads and the DC system can include different kind of devices. The use of this innovative configuration combining AC/DC distribution inside the building has been tested. In this case, the real prototype has a energy storage system based in Lithium-Polymer batteries, a voltage limiter resistor (VLR) and different DC loads, most of them for ventilation and heating purposes. The $\mathrm{AC}$ part and the $\mathrm{DC}$ part are connected through an AC/DC converter. It has been also studied in the simulations the possibility of inserting a PV generator in the DC system. The proposed controls for each element of the system have been tested and the simulations have demonstrated that the system is stable under all possible scenarios. Finally the real tests showed how the system makes the whole building a dispatchable load or generator. In this case it is not possible to achieve a situation where no power is imported from the grid because the prototype is connected to a building with a rated power much higher than the storage system power. Further works should include studies of load profiles and capacities of different storage and generation devices in order to develop a proper sizing procedure to achieve the zero grid impact.

\section{REFERENCES}

[1] J. H. Yoon, R. Baldick, and A. Novoselac, "Dynamic demand response controller based on real-time retail price for residential buildings," Smart Grid, IEEE Transactions on, vol. 5, no. 1, pp. 121-129, Jan 2014.

[2] C. Vivekananthan, Y. Mishra, G. Ledwich, and F. Li, "Demand response for residential appliances via customer reward scheme," Smart Grid, IEEE Transactions on, vol. PP, no. 99, pp. 1-12, 2014.

[3] B. Moradzadeh and K. Tomsovic, "Two-stage residential energy management considering network operational constraints," Smart Grid, IEEE Transactions on, vol. 4, no. 4, pp. 2339-2346, Dec 2013.

[4] M. Sullivan, J. Bode, B. Kellow, S. Woehleke, and J. Eto, "Using residential ac load control in grid operations: Pg amp;e's ancillary service pilot," Smart Grid, IEEE Transactions on, vol. 4, no. 2, pp. 1162-1170, June 2013.

[5] C. Murillo-Sanchez, R. Zimmerman, C. Lindsay Anderson, and R. Thomas, "Secure planning and operations of systems with stochastic sources, energy storage, and active demand," Smart Grid, IEEE Transactions on, vol. 4, no. 4, pp. 2220-2229, Dec 2013.

[6] M. C. Falvo, "Generation \& transmission planning and electricity market: The role of tso," in Energy Market (EEM), 2010 7th International Conference on the European, 2010, pp. 1-6.

[7] R. Argiento, R. Faranda, A. Pievatolo, and E. Tironi, "Distributed interruptible load shedding and micro-generator dispatching to benefit system operations," Power Systems, IEEE Transactions on, vol. 27, no. 2, pp. 840-848, May 2012.

[8] G. Parise, L. Martirano, and L. Parise, "Ecodesign of ever net-load microgrids," Industry Applications, IEEE Transactions on, vol. 50, no. 1, pp. 10-16, Jan 2014.

[9] A. Ipakchi and F. Albuyeh, "Grid of the future," Power and Energy Magazine, IEEE, vol. 7, no. 2, pp. 52-62, March 2009.

[10] P. Kadurek, J. Cobben, W. Kling, and P. Ribeiro, "Aiding power system support by means of voltage control with intelligent distribution substation," Smart Grid, IEEE Transactions on, vol. 5, no. 1, pp. 84-91, Jan 2014.

[11] C. Gonzalez-Moran, P. Arboleya, D. Reigosa, G. Diaz, and J. GomezAleixandre, "Improved model of photovoltaic sources considering ambient temperature and solar irradiation," in Sustainable Alternative Energy (SAE), 2009 IEEE PES/IAS Conference on, 2009, pp. 1-6. 